\title{
NATURAL PHENOLICS IN THE PREVENTION OF UV-INDUCED SKIN DAMAGE. A REVIEW
}

\author{
Alena Svobodová*, Jitka Psotová, Daniela Walterová \\ Institute of Medical Chemistry and Biochemistry, Faculty of Medicine, Palacký University, Hnèvotínská 3, \\ 77515 Olomouc, Czech Republic, alf.svoboda@seznam.cz
}

Received: September 28, 2003; Accepted: October 17, 2003

Key words: UV radiation / Keratinocytes / Fibroblasts / ROS / Photoprotection / Polyphenol / Plant extract

UV skin exposure induces extensive generation of reactive oxygen species (ROS). These can react with DNA, proteins, fatty acids and saccharides causing oxidative damage. Such injuries result in a number of harmful effects: disturbed cell metabolism, morphological and ultrastructural changes, attack on the regulation pathways and, alterations in the differentiation, proliferation and apoptosis of skin cells. These processes can lead to photoaging and skin cancer development.

One approach to protecting human skin against the harmful effects of UV irradiation is to use antioxidants as photoprotectives. In recent years naturally occurring herbal compounds such as phenolic acids, flavonoids, and high molecular weight polyphenols have gained considerable attention as beneficial protective agents.

In this review, we strive to summarize the findings of studies performed to date, regarding the photoprotective effects of plant phenolics on the skin damage induced by UV radiation.

\section{INTRODUCTION}

In recent years, the incidence of various diseases and disorders related to solar ultraviolet radiation has increased alarmingly and continues to grow. Chronic exposure of mammalian skin to UV radiation induces a number of biological responses, including development of erythema, edema, sunburn cell formation, hyperplasia, immune suppression, DNA damage, photoaging and melanogenesis. These alterations are directly or indirectly involved in the development of skin cancer ${ }^{1-3}$.

UV radiation is a very potent initiator of photochemical reactions through excitation of electrons and this can result in energy transfer or chemical modification of the exposed molecule. After absorbing the UV light, the molecule may become damaged and affect other molecules, e.g. by producing reactive oxygen species (ROS). In biological systems, the absorbed light can interact with endogenous photosensitive molecules or/and with exogenous photosenzitizers originating from drugs or cosmetic ingredients. Consequently, these interactions can directly or indirectly produce deleterious, cytotoxic and genotoxic effects ${ }^{4}$.

\section{UV RADIATION AND ITS EFFECTS ON THE SKIN}

UV radiation forms a part of the electromagnetic spectrum with wavelengths between $200 \mathrm{~nm}$ and $400 \mathrm{~nm}$. It is divided into three categories dependent on wavelength, long wave UVA (320-400 nm), medium wave UVB (280-320 nm), and short wave UVC (200-280 nm $)^{5-7}$.
Between 1970 and 1987, substantial damage to the protective ozone layer resulted in an increased amount of UV radiation reaching the earth's surface ${ }^{7}$.

Of this, more than $90 \%$ of solar radiation that reaches us is UVA. This longer wavelength, considered as the "aging ray" penetrates deep into the epidermis and dermis of the skin. Compared to UVB, UVA is about 1000 times more effective in the production of an immediate tanning effect which is caused by darkening of the melanin in the epidermis. Intense or extensive exposure to UVA can burn sensitive skin, and if prolonged, it can damage underlying structures in the corium and cause premature photoaging of the skin. It mainly causes skin sagging rather than wrinkling and it may suppress some immunological functions. UVA-induced responses in cells happen mainly because of oxidative processes initiated by endogenous photosensitization. After UVA exposure, singlet oxygen, $\mathrm{H}_{2} \mathrm{O}_{2}$ and hydroxyl free radicals are generated. These can cause damage to cellular proteins, lipids, and saccharides. UVA injury tends to cause necrosis of endothelial cells, thus damaging the dermal blood vessels. UVA can produce structural damage to the DNA, impair the immune system, and lead to cancer. It has been linked to $67 \%$ of malignant melanoma ${ }^{2,6,8,9}$.

UVB radiation is regarded as the "burning ray" and it makes up 4 to $5 \%$ of UV light. UVB is a minor but the most active constituent of solar light. UVB is 1000 times more capable of causing sunburn than UVA. UVB is also more genotoxic than UVA. UVB acts mainly in the epidermal basal cell layer of the skin. It induces direct and indirect adverse biological effects, including the formation of pyrimidine photoproducts, isomerization of trans- to 
cis-urocanic acid, induction of ornithine decarboxylase activity, stimulation of DNA synthesis, free radical production in the skin, cell cycle growth arrest, photoaging and photocarcinogenesis. It significantly decreases antioxidants in the skin, impairing the skin's ability to protect itself against the free radicals generated by exposure to sunlight. It is considered to be responsible for inducing skin cancer (squamous and basal cell carcinoma) due to DNA damage. It is also suspected of lowering the skin's immune defense system ${ }^{4,6,8,9}$.

UVC is very dangerous to all forms of life, even with only very short exposures. It is extremely damaging to the skin. Fortunately, UVC radiation from the sun is completely absorbed by molecular oxygen and ozone in the earth's atmosphere and no solar radiation of wavelengths below $290 \mathrm{~nm}$ reaches the surface of the earth ${ }^{4,6}$.

To exert its biological effects, UV must be first absorbed by cellular chromophore, which transforms the energy into a biochemical signal. Subsequent photobiochemical reactions provoke changes in cell and tissue biology resulting in increased photoaging and skin cancer occurrence. Nucleic acids and proteins are the major cellular chromophores absorbing radiation in the UVB wavelength range. If DNA absorbs energy within the UVB region of the spectrum this may result in DNA lesions. The main lesions induced by UVB are cyclobutane-pyrimidine dimers and pyrimidine-pyrimidone photoproducts. Blockade of RNA transcription that occurs as a result of DNA photoproduct formation leads to activation of the p53 protein that induces apoptosis of irradiated keratinocytes. Repair of photolesions is the primary response to DNA photodamage in surviving cells. However, if the damage persists into the $\mathrm{S}$ phase of the cell cycle, other repair mechanisms might lead to mutagenesis resulting mainly in characteristic cytosine to thymine substitution. When such mutations occur in the p53 gene, keratinocytes lose their ability to undergo the apoptotic process following high-dose UV exposure. Tryptophan and tyrosine are the main amino acids that absorb UVB. Other biomolecules, acting as radiation absorbents within the UVB range, are NADH, quinones, flavins, porphyrins, 7-dehydrocholesterol, and urocanic acid ${ }^{6,9,10}$. UVA-absorbing cellular molecules in the initiation of UVA-induced photosensitization are still largely unknown, only transurocanic acid was reported ${ }^{9}$.

Damage to skin epidermal cells becomes evident as early as $2 \mathrm{~h}$ after UV irradiation. The initial indicator of damage is a decrease in keratinosomes, which results in the formation of dyskeratotic cells. Intracellular edema can be seen 16-18 $\mathrm{h}$ after exposure, followed at 30-48 $\mathrm{h}$ by intercellular edema that develops around damaged keratinocytes ${ }^{6}$. The sunburn cells were proposed as one of the earliest examples of apoptosis. UV-induced apoptotic cells are rapidly phagocytized by the surrounding keratinocytes. Macrophages are also known to bind and phagocytize apoptotic cells and their number in the skin increases dramatically after UVB treatment ${ }^{6}$.

The degenerative changes in keratinocytes include mitochondrial swelling and rupture, condensation of the cytoplasm and the appearance of pyknotic nuclei. The observed cellular damage is maximal at $48-72 \mathrm{~h}$ for the total UV range ${ }^{6}$.

UV exposure to the skin results in generation of reactive oxygen species ${ }^{11,12}$. ROS are constantly generated in keratinocytes and fibroblasts, and are rapidly removed by nonenzymic and enzymic antioxidant substances. These prevent harmful effects of ROS and maintain a prooxidant/antioxidant balance, thus resulting in cell and tissue stabilization. ROS comprise a number of active metabolites including hydroxyl radical, superoxide anion and peroxyl radical and their active precursors namely singlet oxygen, hydrogenperoxide and ozone. Nitric oxide and nitric dioxide, reactive nitrogen species (RNS), are also generated. Excess of free radicals results in a cascade of events mediating progressive deterioration of cellular structure and function, and this can lead to a loss of cellular integrity by modification of DNA and also to abnormal expression of cellular genes. UV-generated ROS affect mitogen-activated protein kinase (MAPK) signalling cascades. These have been shown to activate nuclear factor kappa B (NF- $\mathrm{kB}$ ), as well as c-Jun N-terminal and p38 MAP kinases followed by activation of transcription factor AP-1 (activation protein 1). Both may contribute to the induction of heme oxygenase-1 (HO-1) and matrix metalloproteinases (MMPs) in the skin. Increased level of HO-1 may elevate cellular levels of iron that can promote further ROS generation. MMPs induction leads to enhanced degradation of extracellular matrix proteins that favor wrinkle formation and metastases. ROS damage cell membranes by peroxidation of fatty acids within the phospholipid structure of the membrane. During this process, lipid peroxide radicals, lipid hydroperoxides and other fragmentation products, that are themselves active oxidizing agents, are formed. The lipid peroxides are comparatively longer-lived species and can initiate the chain reactions that enhance oxidative damage ${ }^{12}$.

Although the skin possesses an elaborate antioxidant system to deal with the UV-induced oxidative stress, extensive and chronic exposure to UV can exceed the cutaneous antioxidant capacity, leading to oxidative damage that may result in skin disorders, immunosuppression and premature skin aging ${ }^{13}$.

One approach to protecting humans from the harmful effects of UV irradiation is to use active photoprotectives. In recent years, naturally occurring compounds have gained considerable attention as protective agents. Vitamins $\mathrm{C}, \mathrm{E}$, and $\beta$-carotene have been incorporated into many skin care products for instance. Another approach is afforded by the antioxidative properties of phenolics. These substances can be used as ingredients in human diet or added to preparations for topical application ${ }^{1,5,8}$.

\section{PHENOLICS}

The term phenolics ecompasses approximately 8000 naturally occurring compounds, all of which possess one common structural feature, a phenol (an aromatic ring 
bearing at least one hydroxyl substituent). Phenolics are plant secondary metabolites and they are commonly found in herbs and fruit (e.g. berries, apples, citrus fruit, cocoa, grapes, apricots, peaches, cherries, plums), vegetables (e.g. onions, olives, tomatoes, broccoli, lettuce, soybeans, nuts, spinach, cabbage, artichokes, eggplants), grains (e.g. wild rice), tea (green and black), coffee beans, propolis, and red wine as a colour and flavouring agents and are an integral part of human diet ${ }^{14-21}$.

The three important groups for humans are phenolic acids, flavonoids, and high-molecular weight polyphenols ${ }^{22,23}$. Naturally occurring phenolic acids contain two distinguishing constitutive carbon frameworks: the hydroxycinnamic and hydroxybenzoic acid structures ${ }^{22}$. The flavonoids consist of a large group of low-molecular weight polyphenolic substances, benzo- $\gamma$-pyrone derivatives that are diverse in chemical structure. High-molecular weight polyphenols, commonly known as tannins, are polymer compounds. They are divided into two groups: condensed (polymers of catechines or epicatechines) and hydrolysable (polymers of gallic or ellagic acids) ${ }^{23}$. The phenolics, particularly polyphenols exhibit a wide variety of beneficial biological activities in mammals, including antiviral, antibacterial, immune-stimulating, antiallergic, antihypertensive, antiischemic, antiarrhytmic, antithrombotic, hypocholesterolemic, antilipoperoxidant, hepatoprotective, anti-inflammatory, and anti-carcinogenic actions. They are powerful antioxidants in vitro ${ }^{14,18,19,24-27}$. In a structure-dependent manner, flavonoids and phenolic acids are capable of scavenging ROS, RNS and chelating transition metal ions such as iron and copper, which play vital roles in the initiation of free radical reactions ${ }^{19,28-30}$. Several studies have shown the flavonoids to act as scavengers of superoxide anions, singlet oxygen, hydroxyl radicals, and lipid peroxyl radicals ${ }^{31,32}$. There are also reports of flavonoids inhibiting the activities of many enzymes, including lipoxygenase, cyclooxygenase, monooxygenase, xantinoxidase, mitochondrial succinate dehydrogenase and NADH-oxidase, phospholipase $\mathrm{A}_{2}$, protein kinases, and nuclear transcription factor $(\mathrm{NF}-\mathrm{kB})^{33,34}$.

Phenolics are believed to be capable of acting in redoxsensitive signalling cascades to inhibit DNA damage ${ }^{19}$. In contrast to their beneficial effect, some phenolics however have also been found in vitro to be mutagenic. These harmful effects are suspected to result from the prooxidant rather than antioxidant action of these compounds. Therefore it is necessary to investigate their toxic effects before human use ${ }^{33}$.

In the past decade, the antioxidant activity of herbal phenolics, namely phenolic acids and flavonoids has been given much attention. Many flavonoids such as quercetin, luteolin and catechins are better antioxidants than the nutrients vitamin $\mathrm{C}$, vitamin $\mathrm{E}$ and $\beta$-carotene ${ }^{25}$. Therefore, the phenolics may be beneficial in preventing UV-induced oxygen free radical generation and lipid peroxidation, i.e. events involved in pathological states such as photoaging and skin cancer.

This review is a summary of the findings of the photoprotective effects of some naturally occurring herbal polyphenols and phenolic rich extracts in studies of the skin damage induced by UV irradiation.

\section{Caffeic and ferulic acids}

Caffeic acid (3,4-dihydroxycinnamic acid) and ferulic acid (4-hydroxy-3-methoxycinnamic acid) are largely present in grains, fruit and vegetables where they are conjugated with saccharides ${ }^{35}$.

These two acids have been demonstrated to protect phospholipidic membranes from UV-induced peroxidation by inhibiting propagation of the lipid peroxidative chain reaction and to react with nitrogen oxides ${ }^{36}$. Caffeic acid and, at a greater degree, ferulic acid proved effective in protecting human skin from UVB-induced erythema. Ferulic acid, shown to be a strong UV absorber, is employed as a photoprotective agent in a number of skin lotions and sunscreens ${ }^{37}$.<smiles>O=C(O)/C=C/c1ccc(O)c(O)c1</smiles>

Caffeic acid<smiles>COc1cc(/C=C/C(=O)O)ccc1O</smiles>

Ferulic acid

\section{Quercetin}

Quercetin (3,5,7,3',4'-pentahydroxyflavon) is one of the most abundant natural flavonoids. It is present in various common fruit and vegetables (apples, grapes, lemons, tomatoes, onions, lettuce, broccoli, kale, cottonseed etc.), beverages (tea, red wine), herbs (Gingko biloba, Apocynum venetum, Poacynum hendersonii, Opuntia ficusindica), olive oil, and propolis from bee hives ${ }^{11,38}$.

As a powerful antioxidant and metal ion chelator, quercetin is believed capable of preventing the harmful effects of UV light or at least of reducing the damage ${ }^{38}$. Inal et al. showed that quercetin protected skin antioxidant systems, namely glutathione peroxidase, glutathione reductase, catalase and superoxide dismutase activities, against UVA irradiating damage in rats to a considerable degree $^{11}$. Oral intake of quercetin prevented UVB-induced immunosuppression in SKH-1 hairless mice ${ }^{39}$. In vitro, quercetin and its semisynthetic derivatives (quercetin 3-O-acetate, quercetin 3-O-propionate, quercetin 3-Opalmitate) were found to inhibit UVC radiation-induced peroxidation in liposomal membranes ${ }^{40}$. 
<smiles>O=c1c(O)c(-c2ccc(O)c(O)c2)oc2cc(O)cc(O)c12</smiles>

Quercetin hairless mice skin substantially inhibited the UVB-induced $\mathrm{H}_{2} \mathrm{O}_{2}$ production, contact hypersensitivity and reduced the inflammatory edema reaction. Equol was the most effective of them ${ }^{48}$.<smiles>O=c1c(-c2ccc(O)cc2)coc2cc(O)cc(O)c12</smiles>

Genistein

\section{Apigenin}

Apigenin (5,7,4'-trihydroxyflavone) is a widely distributed plant flavonoid occurring in herbs (e.g. endive, clove), fruit (e.g. apples, cherries, grapes), vegetables (e.g. beans, broccoli, celery, leeks, onions, barley, parsley, tomatoes) and beverages (e.g. tea, wine $)^{8}$.

Apigenin was found to be effective in the prevention of UVA/B-induced skin carcinogenesis in SKH-1 mice. When applied topically it inhibited UV-mediated induction of ornithine decarboxylase activity, reduced tumour incidence and increased tumour free survival ${ }^{41,42}$. Several studies have provided evidence that apigenin may prevent UV-induced skin tumorigenesis by inhibiting the cell cycle and cyclin-dependent kinases (cdk). Apigenin treatment of mouse keratinocytes induced $\mathrm{G} 2 / \mathrm{M}$ cell cycle arrest, accumulation of the p53 tumor suppressor protein and expression of its downstream effector (a cdk inhibitor p21/WAF 1$)^{41}$. This arrest was also accompanied by inhibition of $\mathrm{p} 34 / \mathrm{cdk} 2$ kinase protein level and activity, which was found independent of p21/WAF1(ref. $\left.{ }^{8}\right)$. In human diploid fibroblasts apigenin produced $\mathrm{G} 1$ cell-cycle arrest by inhibiting cdk 2 kinase activity and inducing $\mathrm{p} 21 / \mathrm{WAF} 1$ $\left(\right.$ ref. $\left.^{43}\right)$<smiles>O=c1cc(-c2ccc(O)cc2)oc2cc(O)cc(O)c12</smiles>

Apigenin

\section{Genistein}

Genistein (5,7,4'-trihydroxyisoflavone) occurs in plants. In particular, it is the major component of soybeans ${ }^{44}$. Genistein is also able to modulate cell cycling and to prevent cancer in many organ systems $\mathrm{s}^{45,46}$.

Genistein inhibited UVB-induced protooncogene expression and skin tumorigenesis in hairless mice ${ }^{47}$. Topical application of genistein and its gastrointestinal metabolites such as equol, isoequol and dehydroequol to

\section{Resveratrol}

Resveratrol (trans-3,5,4'-trihydroxystilbene) is a naturally occurring polyphenolic phytoalexin amply present in the skin and seeds of grapes. Other plant sources include peanuts, red wine and berries ${ }^{49}$. Resveratrol is an effective antioxidant with strong anti-inflammatory and antiproliferative activity. It also shows inhibitory effects on diverse cellular processes associated with tumour initiation, promotion and progression ${ }^{5,8}$.

Topical application of resveratrol to SKH-1 hairless mice resulted in significant inhibition of UVB-induced skin edema. Resveratrol pre-treatment caused a decrease in UVB-induced generation of hydrogen peroxide and infiltration of leukocytes ${ }^{5}$. In addition, topical application of resveratrol substantially reduced UVB-induced lipid peroxidation, cyclooxygenase and ornithine decarboxylase activities, and protein expression of the latter enzyme ${ }^{50}$. In normal human epidermal keratinocytes, resveratrol blocks UVB-mediated activation of NF- $\mathrm{kB}$ in a dose- and time-dependent manner ${ }^{51}$.<smiles>[R]C(C)C</smiles>

Nordihydroguaiaretic acid

Nordihydroguaiaretic acid (1,4-(3,4-dihydroxyphenyl)-2,3-dimethylbutane) is a polyphenolic compound from the Larrea tridentate bush that has been identified as a chemopreventive drug in animal studies.

Nordihydroguaiaretic acid (NDGA) significantly inhibited UVB-induced c-fos and AP-1 transactivation in the HaCaT keratinocyte cell line. In addition, NDGA was found to reduce the activity of phosphatidylinositol 3-kinase which is the UVB-inducible enzyme involved in the expression of AP-1 and its component proteins c-Fos ${ }^{52}$. 


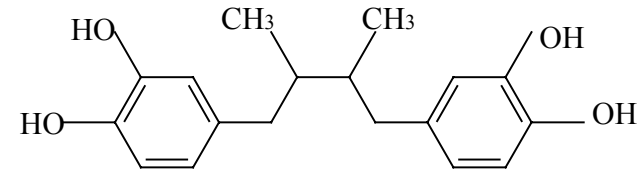

Nordihydroguaiaretic acid

\section{Carnosic acid}

This is the major constituent of rosemary (Rosmarinus officinalis) and sage (Salvia officinalis), and it has powerful antioxidant action ${ }^{53}$. Chemoprotective effects against carcinogens have been identified when this acid is tested in animals ${ }^{54}$.

Pretreatment of human fibroblasts with carnosic acid resulted in suppression of metalloproteinase- 1 mRNA elevation caused by UVA irradiation ${ }^{55}$.<smiles>CC(C)c1cc2c(c(O)c1O)C1(C(=O)O)CCCC(C)(C)C1CC2</smiles>

Carnosic acid

\section{Silymarin}

Silymarin is a standardized extract of flavonolignans from the seeds of the milk thistle, Silybum marianum (L.) Gaertner. The main components of silymarin include silybin, silidianin, silychristin and isosilybin. Silybin is considered to be the principal biologically active constituent with regard to its antioxidant and anti-inflammatory properties. Silymarin has been widely used in traditional European medicine for two thousand years, especially for the treatment of liver diseases. Several papers have also reported its skin cancer chemoprotective action ${ }^{5,56-58}$.

Topical application of silymarin was found to result in significant inhibition of UVB-induced skin edema, formation of sunburn and apoptotic cells. It also caused depletion of catalase, induction of cyclooxygenase and ornithine decarboxylase in mouse models ${ }^{59}$. Topical application of silymarin resulted in protection against UVBinduced formation of cyclobutane-pyrimidine dimers in mouse skin ${ }^{5}$. Treatment with silymarin prevented UV-induced infiltration of inflammatory leukocytes, which are responsible for induction of UV-induced oxidative stress in the skin. Application of silymarin to mouse skin also resulted in significant reduction in the number of UVBinduced hydrogen peroxide producing cells and inducible nitric oxide synthase expressing cells ${ }^{60}$. Silymarin showed a dose dependent protective effect against UV-induced damage in human keratinocytes via inhibition of NF-kB activation $^{61}$.<smiles>COc1cc(C2Oc3cc([C@@H]4Oc5cc(O)cc(O)c5C(=O)C4O)ccc3OC2CO)ccc1O</smiles>

Silybin

\section{Tea polyphenols}

Tea (Camelia sinensis), one of the most consumed beverages in the world, is grown in about 30 countries $^{62}$. The main antioxidant polyphenols present in black and green tea are known as epicatechins or epicatechin derivatives. The major epicatechins found in green tea include (-)-epicatechin (EC), (-)-epicatechin-3-gallate (ECG), (-)-epigallocatechin (EGC), and (-)-epigallocatechin-3gallate $(\mathrm{EGCG})^{13}$. EGCG forms $60-70 \%$ of the total amount of catechins ${ }^{62}$.

These polyphenols have been shown to function as anti-inflammatory or anticarcinogenic agents in various biological systems. Of these substances, EGCG has been shown to be the most effective chemoprotective agent against cutaneous inflammatory or carcinogenic responses ${ }^{63}$.

In recent years, a wide range of studies using several tumour bioassay protocols have demonstrated that topical application of polyphenolic fraction isolated from green and black tea show significant chemoprevention effects against each stage of skin carcinogenesis in the mouse skin model ${ }^{62}$. In hairless mice, both chronic oral feeding and topical application of green tea polyphenols (GTP) was found to result in significant protection against UVBinduced cutaneous edema and erythema, lipid peroxidation, depletion of epidermal antioxidant-defence enzyme system and formation of prostaglandin metabolites ${ }^{13,64}$. Using in vitro system, Wei at al. have shown that aqueous extracts of green and black tea scavenge $\mathrm{H}_{2} \mathrm{O}_{2}$ and inhibit UV-induced oxidative DNA single strand damage ${ }^{5,64}$. Topical application of GTP prior to UVB irradiation resulted in reduced production of cyclobutane-pyrimidine dimers in epidermis and dermis of human skin. This reduction is probably due to protection of DNA repair enzymes from inactivation by ROS and due to absorption of UV energy by EGCG $\left(I_{\max } 270-273 \mathrm{~nm}\right)^{5}$. Green tea polyphenols (GTP) induce apoptosis in human epidermal carcinoma cells and human carcinoma keratinocytes ${ }^{63}$. Recently, topical application of EGCG before exposure has been shown to significantly reduce UVB-induced development of erythema, myeloperoxidase activity, $\mathrm{H}_{2} \mathrm{O}_{2}$ and $\mathrm{NO}$ production, and epidermal lipid peroxidation in human $\operatorname{skin}^{63,65}$. It was also found to block UV-induced leukocyte infiltration. The addition of EGCG to tumour cells results in G0-G1 cell cycle arrest. It has been concluded that GTP may reduce tumour development by arresting transformed cells in the G0-G1 phase and removing them by augmenting apoptosis ${ }^{65}$. 
<smiles>Oc1cc(O)c2c(c1)O[C@H](c1ccc(O)c(O)c1)[C@H](O)C2</smiles>

(-)-Epicatechin<smiles>O=C(O[C@H]1Cc2c(O)cc(O)cc2O[C@@H]1c1ccc(O)c(O)c1)c1cc(O)c(O)c(O)c1</smiles>

(-)-Epicatechin-3-gallate<smiles>Oc1cc(O)c2c(c1)O[C@H](c1cc(O)c(O)c(O)c1)[C@H](O)C2</smiles>

(-)-Epigallocatechin<smiles>O=C(O[C@H]1Cc2c(O)cc(O)cc2O[C@@H]1c1cc(O)c(O)c(O)c1)c1cc(O)c(O)c(O)c1</smiles>

(-)-Epigallocatechin-3-gallate

\section{Tannins}

Tannins are polyphenolic compounds widely distributed in the plant kingdom and are believed to provide in plants a chemical defence against predators and ultraviolet radiation. They are classified into two major categories, hydrolysable tannins (HTs) which include gallotannins and ellagotannins, and condensed tannins (CTs), proanthocyanidins ${ }^{66,67}$.

These plant polyphenols are potent antioxidants that may protect against free radical damage caused by exposure to UV light and, in turn, reduce the risk of skin cancer and premature aging. HTs and CTs plant samples administered topically or injected intraperitoneally have been shown to reduce $\mathrm{H}_{2} \mathrm{O}_{2}$ production, decrease tumor incidence or delay their appearance in the skin of hairless mice. In addition, they inhibit induction of ornithine decarboxylase and stimulation of epidermal DNA synthesis, to a remarkable extent ${ }^{66,67}$.<smiles>Oc1cc(O)c2c(c1)OC(c1ccc(O)c(O)c1)C(O)C2c1c(O)cc(O)c2c1CC(c1ccc(O)c(O)c1)C(O)C2</smiles>

Procyanidin B1

\section{Capparis spinosa extract}

The flower buds of $C$. spinosa have been used for several purposes since ancient times. These plants are widely distributed in tropical or subtropical as well as arid areas of the world ${ }^{68}$. The major constituents of lyophylized extract of $C$. spinosa (LECS) have been identified as kaempferol and quercetin derivatives and caffeic, ferulic, p-cumaric, and cinnamic acids. LECS show significant antioxidant effect ${ }^{69}$.

Topically applied LECS reduces UVB-induced skin erythema in healthy human volunteers ${ }^{69}$.

\section{Culcitium reflexum H.B.K. leaf extract}

C. reflexum H.B.K is a herbaceous plant grown in South America, especially in Ecuador and Columbia. The local folk used it for the treatment of some skin inflammatory conditions. $C$. reflexum leaves contain a large amount of phenolic compounds, especially flavonols. The main constituents have been identified as rutin, kaempferol, quercetin and its glucosylated derivates and some cinnamic acid derivates. Ethanolic extract of $C$. reflexum possesses a strong antioxidant or free radical scavenging effect.

Topical application of $C$. reflexum extract in the form of a gel has proven to be a significant in vivo protection against UVB-induced skin erythema in healthy human volunteers ${ }^{70}$.

\section{French maritime pine bark extract}

Pycnogenol ${ }^{\circledR}$ is the trade name of a standardized extract of the French maritime pine (Pinus pinaster) bark. The extract is a mixture of phenols and polyphenols (procyanidin derivates, catechin, epicatechin, taxifolin) and phenolic acids (caffeic, ferulic, $p$-hydroxybenzoic, vanillic, gallic, protocatechuic $)^{71,72}$.

Pycnogenol ${ }^{\circledR}$ has been found to have excellent free radical scavenger properties by enhancing the production 
of antioxidative enzymes ${ }^{72}$. It has been found to inhibit UV-induced NF-kB-dependent gene expression in a concentration dependent manner in HaCaT keratinocytes ${ }^{71}$. Topical application of a gel containing pycnogenol significantly prevented UV-induced erythema in rat ${ }^{73}$. Same effect was observed in human after oral intake ${ }^{71}$.

\section{Ginkgo biloba extract}

G. biloba extract (EGb 761) is a well-defined product prepared from the green leaves of the $G$. biloba tree. This is a natural mixture containing flavone glycosides (33\%), mostly quercetin and kaempferol derivatives, and terpenes (6\%). In man, EGb 761 is used or experimented on for the treatment of pathologic conditions like stroke, aging, and some drug induced toxicities. It has been demonstrated to stop lipoperoxidation by quenching the peroxyl radical $^{74,75}$

$\mathrm{EGb} 761$ has been also found to decrease the number of UVB-induced sunburn cells in mice $\operatorname{skin}^{75}$. Oral administration of $G$. biloba extract leads to increased superoxide dismutase activity in UVB-irradiated mice skin $^{76}$.

\section{Grape seed extract}

Grapes are one of the most consumed fruits in the world. Grapes are rich in polyphenols and 60-70\% of grape polyphenols are found in grape seeds. Grape seed polyphenols (GSP) include flavan-3-ol derivatives - catechin, epicatechin and oligomeric proanthocyanidins ${ }^{77}$ GSP exert anti-inflammatory, anti-apoptotic, anti-necrotic and anticarcinogenic activities, and have beneficial effects against several diseases, including skin aging and cancer ${ }^{78}$. GSP have been shown to exert a much stronger oxygen free radical scavenging effect than vitamin $\mathrm{C}$ and $\mathrm{E}$ and to prevent UVB- and UVC-induced lipid peroxidation ${ }^{77,79}$. Dietary feeding of GSP to SKH-1 hairless mice resulted in prevention of UVB-induced photocarcinogenesis in terms of reduced tumor incidence, tumor multiplicity and tumor size. It also resulted in reducing malignant transformation of UVB-induced papillomas to carcinomas ${ }^{79}$.

\section{Krameria triandra root extract}

Rhatany, the dried roots of $K$. triandra Ruiz and Pavon, are used in herbal preparations for a variety of systemic and topical disorders. The extract contains phenolic constituents, low molecular weight neolignans and medium high molecular weight oligomeric proanthocyanidins.

Extract of $K$. triandra has shown protective effects against UVB-induced photodamage in human keratinocyte cells ${ }^{80}$.

\section{Prunus persica flower extract}

The flowers of $P$. persica have been used for skin disorders in East Asia from ancient times. They contain four kaempferol glycoside derivatives (multiflorin B, trifolin, afzelin, and astragalin $)^{81}$.

$P$. persica extract has been demonstrated to possess protective activity against $\mathrm{UV}$-induced cytotoxicity in keratinocytes and fibroblasts ${ }^{82}$. It inhibits UVB/ UVCinduced DNA damage and lipid peroxidation in skin fibroblasts ${ }^{83}$ and, the quantity of $14 \mathrm{C}$-arachidonic acid/ metabolites released from UVB-irradiated human keratinocytes ${ }^{81}$. Both the extract and multiflorin B inhibit dose dependently UVB-induced erythema formation in guinea pigs when topically applied ${ }^{81}$. The extract was also shown to delay tumour development after UVB-induced skin carcinogenesis in SKH-1 hairless mice. It also reduces UVB-induced ear edema in IRC mice ${ }^{83}$.

\section{Sanguisorba officinalis L. root extract}

S. officinalis L. is found in China, Korea, Japan Siberia and Europe ${ }^{84}$. Hydrolysable tannins are reported as characteristic constituents of $S$. officinalis roots and are considered to be partially responsible for the therapeutic effects of this crude drug ${ }^{85}$.

Topical application of $S$. officinalis L. extract following UVB exposure inhibited wrinkle formation, maitained skin elasticity and prevented the decrease of dermal elastic fiber linearity in the rat hind limb skin in a dose dependent manner ${ }^{86}$.

\section{Sedum telephium L. leaf extract}

The leaves or fresh juice of S. telephium L. were widely used in antiquity to cure many types of inflammatory skin diseases. S. telephium L. leaves contain polysaccharides, gallic acid, and flavonol glycosides (quercetin and kaempferol).

Gel formulations of both the total lyophilised juice and, to a greater degree, the lyophilised flavonolic fraction appear to possess potent protective effects against UV-induced skin erythema in human volunteers ${ }^{87}$.

\section{CONCLUSION}

Human skin is constantly exposed to the UV irradiation present in sunlight. This may induce a number of pathobiological cellular changes. The development of novel preventive and therapeutic strategies depends on our understanding of the molecular mechanism of UVdamage.

Plant phenolics are one candidate for prevention of the adverse effects of UV radiation on the skin and evaluation of their clinical efficacy is awaited.

\section{ACKNOWLEDGEMENTS}

This work was supported by the internal LF UP grant No. 11501109, GA ČR grant No. 303/02/1097 and Ministry of Education grant MSM 151100003.

\section{REFERENCES}

1. Tebbe B. (2001) Relevance of oral supplementation with antioxidant for prevention and treatment of skin disorders. Skin Pharmacol Appl Skin Physiol 14, 296-302.

2. Afag F, Mukhtar H. (2001) Effects of solar radiation on cutaneous detoxification pathways. J Photochem Photobiol B 63, 61-9. 
3. Goihman-Yahr M. (1996) Skin Aging and Photoaging: An Outlook Clin Dermatol 14, 153-60.

4. De Gruijl RR. (2002) Photocarcinogenesis: UVA vs. UVB radiation. Skin Pharmacol Appl SkinPhysiol 15, 316-20.

5. Afaq F, Adhami VM, Ahmad N, Mukhtar H. (2002) Botanical antioxidants for chemoprevention of photocarcinogenesis. Front Biosci 7, 784-92.

6. Clydesdale GJ, Dandie GW, Muller HK. (2001) Ultraviolet light induced injury: Immunological and inflammatory effests. Immunol Cell Biol 79, 547-68.

7. Duthie MS, Kimber I, Norval M. (1999) The effects of ultraviolet radiation on the human immune system. Br J Dermatol 140, 995-1009.

8. Afaq F, Mukhtar H. (2002) Photochemoprevention by botanical antioxidants. Skin Pharmacol Appl Skin Physiol 15, 297-306.

9. Trautinger F. (2001) Mechanisms of photodamage of the skin and its functional consequences for skin agening. Clin Exp Dermatol 26, 573-7.

10. Kulms D, Schwarz T. (2000) Molecular mechanisms of UV-induced apoptosis. Photodermatol Photoimmunol Photomed 16 195-201.

11. Inal ME, Kahramant A, Kökent T (2001) Beneficial effects of quercetin on oxidative stress induced by ultraviolet A. Clin Exp Dermatol 26, 536-9.

12. Thiele J, Elsner P. Oxidants and antioxidants in cutaneous biology. Basel: Karger, 2001.

13. Katiyar SK, Elmets CA. (2001) Green tea antioxidants and skin photoprotection. Int J Oncol 18, 1307-13.

14. Ross JA, Kasum CM. (2002) Dietary flavonoids: bioavailability, metabolic effects, and safety. Annu Rev Nutr 22, 19-34.

15. Hertog MGL, Hollman PCH, Katan MB, Kromhout D. (1993) Intake of potentially anticarcinogenic flavonoids and their determinants in adults in The Netherlands. Nutr Cancer 20, 21-9.

16. Brit DF, Hendrich S, Wang W. (2001) Dietary agents in cancer prevention: flavonoids and isoflavonoids. Pharmacol Ther 90, 157-77.

17. Kris-Etherton PM, Hecker KD, Bonanome AB, Coval SM, Binkoski AE, Hilpert KF, Griel AE, Etherton TD. (2002) Bioactive compounds in foods: their role in the prevention of cardiovascular disease and cancer. A Symposium: Bioactive compounds in foods. Am J Med 113, 71-88.

18. Robak J, Gryglewski RJ. (1996) Bioactivity of flavonoids. Pol J Pharmacol 48, 555-64.

19. Rice-Evans C, Spencer JE, Schroeter H, Rechner AR. (2000) Bioavailability of flavonoids and potential bioactive forms in vivo. Drug Metabol Drug Interact 17, 1-4.

20. Clifford MN. (1999) Chlorogenic acids and other cinnamatesnature, occurrence and dietary burden. J Sci Food Agric 79 362-72.

21. Rencher AR, Spencer PE, Kuhnle G, Hahn U, Rice-Evans CA (2001) Novel biomarkers of the metabolism of caffeic acid derivates in vivo. Free Radic Biol Med 30, 1213-22.

22. Robbins RJ. (2003) Phenolic acids in food: an overview of analytical methodology. J Agric Food Chem 51, 2866-87.

23. King A, Young G. (1999) Characteristics and occurence of phenolic phytochemicals. J Am Diet Assoc 99, 213-8.

24. Formica JV, Regelson W. (1995) Review of the biology of quercetin and related bioflavonoids. Food Chem Toxicol 33, 1061-80.

25. Gao Z, Huang K, Xu H. (2001) Protective effects of flavonoids in the roots of Scutellaria baicalensis Georgii against hydrogen peroxide-induced oxidative stress in HS-SY5Y cells. Pharmacol Res 43, 173-8.

26. Formica JV, Regelson W. (1995) Review of the quercetin and related bioflavonoids. Food Chem Toxicol 12, 1061-80.

27. Fahim FA, Esmat AY, Fadel HM, Hassan KF. (1999) Allied studies on the effect of Rosmarinus officinalis L. on experimental hepatotoxicity and mutagenesis. Int J Food Sci Nutr 50, 413-27.

28. Anafas'ev IB, Dorozhko AI, Brodskii AV, Koytyuk VA, Potapovitch AI. (1989) Chelating and free radical scavenging mechanisms of inhibitory action of rutin and quercetin in lipid peroxidation. Biochem Pharmacol 38, 1763-9.
29. Van Acker S, van Balen GP, van den Berg DJ, Bast A, van der Vijgh WJ (1998) Influence of iron chelation on the antioxidant activity of flavonoids. Biochem Pharmacol 56, 935-43.

30. Bourne LC, Rice-Evans C (1998) Bioavailability of ferulic acid. Biochem Biophys Res Commun 253, 222-7.

31. Torel J, Cillard J. (1986) Antioxidant activity of flavonoids and reactivity with peroxy radical. Phytochemistry 25, 383-385.

32. Robak J, Gryglewski RJ. (1988) Flavonoids are scavengers of superoxide anions. Biochem Pharmacol 37, 837-41.

33. Morton LW, Caccetta RAA, Puddey IB, Croft KD. (2000) Chemistry and biological effect of dietary phenolic compounds: relevance to cardiovascular disease. Clin Exp Pharmacol Physiol 27, 152-9.

34. Cao G, Sofic E, Prior RL. (1996) Antioxidant and prooxidant behavior of flavonoids: structure-activity relationships. Free Radic Biol Med 5, 749-60.

35. Bourne LC, Rice-Evans C. (1998) Bioaviability of ferulic acid. Biochem Biophys Res Commun 253, 222-7.

36. Saija A, Tomatino A, Lo Cascio R, TrombettaD, Proteggente A, De Pasquale A, UccellaN, Bonina F. (1999) Ferulic and caffeic acids as potential protective agents against photooxidative skin damage. J Sci Food Agric 79, 476-80.

37. Saija A, Tomatino A, Trombetta D, De Pasquale A, Uccella N, Barbuzzi T, Paolino D, Bonina F. (2000) In vitro and in vivo evaluation of caffeic and ferulic acids as topical photoprotective agents. Int J Pharm 199, 39-47.

38. Sestili P, Guidarelli A, Dacha M, Cantoni O. (1998) Quercetin prevents DNA single strand breakage and cytotoxicity by tertbutylhydropreroxide: free radical scavenging versus iron chelating mechanisms. Free Radic Biol Med 25, 196-200.

39. Steerenberg PA, Garssen J, Dortant PM, van der Vliet H, Geerse E, Verlaan AP, Goettsch WG, Sontag Y, Bueno-de-Mesquita HB, van Loveren H. (1997) The effect of oral quercetin on UVB-induced tumor growth and local immunosuppression in SKH-1. Cancer Lett 114, 187-9.

40. Saija A, Tomaino A, Trombetta D, Pellegrino ML, Tita B, Messina C, Bonina FP, Rocco C, Nicolosi G, Castelli F. (2003) In vitro antioxidant and photoprotective properties and interaction with model membranes of three new quercetin esters. Eur J Pharm Biopharm 56, 167-74.

41. Birt DF, Mitchell D, Gold B, Pour P, Pinch HC. (1997) Inhibition of ultraviolet light induced skin carcinogenesis in SKH-1 mice by apigenin, a plant flavonoid. Anticancer Res 17, 85-92.

42. Mc Vean M, Xiao H, Isobe K, Pelling JC. (2001) Increase in wildtype 53 stability and transactivational activity by the chemoprotective agent apigenin in keratinocytes. Carcinogenesis 21, 633-9.

43. Leplez DM, Pelling JC. (1997) Induction of p21/waf1 and G(1) cell-cycle arrest by the chemopreventive agent apigenin. Mol Carcinog 19, 74-82.

44. Polkowski K, Mazurek AP. (2000) Biological properties of genistein. A review of in vitro and in vivo data. Acta Pol Pharm 57, 135-55.

45. Salvi M, Brunati AM, Clari G, Toninello A. (2002) Interaction of genistein with the mitochondrial electron transport chain results in opening of the membrane transition pore. Biochim Biophys Acta 1556, 187-96.

46. Wei H, CaiQ, Rahn RO. (1996) Inhibition of UV light- and fenton reaction-induced oxidative DNA damage by the soybean isoflavone genistein. Carcinogenesis 17, 73-7.

47. Wang Y, Yaping E, Zhang X, Lebwohl M, DeLeo V, Wei H. (1998) Inhibition of ultraviolet (UVB-induced) c-fos and c-jun expression in vivo by protein kinase inhibitor genistein. Carcinogenesis 19, 649-54.

48. Widyarini S, Spinks N, Husband AJ, Reeve VE. (2001) Isoflavonoid compounds from red clover (Trifolium pratense) protect from inflammation and immune suppression induced by UV radiation. Photochem Photobiol 74, 465-70.

49. Jang M, Cai L, Udeani GO, Slowing KV, Thomas CF, Beecher CW, Fong HH, Farnsworth NR, Kinghorn AD, Medta RG, Moon CR, Pezzuto JM. (1997) Cancer chemopreventive activity of resveratrol, a natural product derived from grapes. Science 275, 218-20. 
50. Afaq F, Ahmad VM, Ahmad M. (2003) Prevention of short-term ultraviolet B radiation-mediated damages by resveratrol in SKH-1 hairless mice. Toxicol Appl Pharmacol 186, 28-37.

51. Adhami VM, Afaq F, Ahmad N. (2003) Suppression of ultraviolet B exposure-mediated activation of NF-kappaB in normal human keratinocytes by resveratrol. Neoplasia 5, 74-82.

52. Gonzales M, Bowden GT. (2002) Nordihydroguaiaretic acid-mediated inhibition of ultraviolet B-induced activator protein-1 activation in human keratinocytes. Mol Carcinog 34, 102-11.

53. Masuda T, Inaba Y, Maekawa T, Takeda Y, Tamura H, Yamaguchi H. (2002) Recovery mechanism of the antioxidant activity from carnosic acid quinone, anoxidized sage and rosemary antioxidant. J Agric Food Chem 50, 5863-9.

54. Danilenko M, Wang X, Studzinski GP. (2001) Carnosic acid and promotion of monocytic differentiation of HL60-G cells initiated by other agents. J Natl Cancer Inst 15, 1224-33.

55. Offord EA, Gautier JC, Avanti O, Scaleta C, Runge F, Kramer K, Applegate LA. (2002) Photoprotective potential of lycopene, $\beta$-carotene, vitamin $\mathrm{E}$, vitamin $\mathrm{C}$ and carnosic acid in UVA-irradiated human skin fibroblasts. Free Radic Biol Med 23, 1293-303.

56. Singh RP, Agarwal R. (2002) Flavonoid antioxidant silymarin and skin cancer. Antioxid Redox Signal 4, 655-63.

57. Morazzoni P, Bombardelli E. (1994) Silybum marianum (Cardus marianus). Fitoterapia 66, 3-22.

58. Šimánek V, Walterová D, Vičar J, Urbaníková J, Křen V, Modrianský M, Škotová T, Ulrichová J. (2001) "Silymarin” - extrakt z ostropestře mariánského (Silybum marianum) - lék nebo potravní doplněk. Čes Slov Farm 50, 66-9.

59. Katiyar SK, Korman NJ, Mukhtar H, Agarwal R. (1997) Protective effects of silymarin against photocarcinogenesis in a mouse skin model. J Natl Cancer Inst 89, 556-66.

60. Katiyar SK. (2002) Treatment of silymarin, a plant flavonoid, prevents ultraviolet light-induced immune suppression and oxidative stress in mouse skin. Int J Oncol 21, 1213-222.

61. Saliou C, Kitazawa M, McLaughlin L, Yang JP, Lodge JK, Tetsuka T, Iwasaki K, Cillard J, Okamoto T, Packer L. (1999) Antioxidants modulate acute solar ultraviolet radiation-induced NF-kappa-B activation in a human kerationcyte cell line. Free Radic Biol Med 26, 174-83.

62. Katiyar SH, Mukhtar H. (1997) Tea antioxidants in cancer chemoprevention. J Cell Biochem Suppl 27, 59-67.

63. Katiyar SH, Ahmad N, Mukhtar H. (2000) Green tea and skin. Arch Dermatol 136, 989-94.

64. Wei H, Zhang X, Zhao JF, Wang ZY, Bickers DR, Lebwohl M. (1999) Scavenging of hydrogen peroxide and inhibition of ultraviolet lihgt-induced oxidative DNA damage by aqueous extracts from green and black teas. Free Radic Biol Med 26, 1427-1435.

65. Katiyar SH, Afag F, Perez A, Mukhtar H. (2001) Green tea polyphenol (-)-epigallocatechin-3-gallate treatment of human skin inhibits ultraviolet radiation-induced oxidative stress. Carcinogenesis 22, 287-94.

66. Gali-Muhtasib HU, Yamout SZ, Sidani MM. (1999) Plant tannins as inhibitors of hydroperoxide production and tumor promotion induced by ultraviolet $\mathrm{B}$ radiation in mouse skin in vivo. Oncol Rep $6,547-83$.

67. Gali-Muhtasib HU, Yamout SZ, Sidani MM. (1999) Tannins protect against skin tumor promotion induced by ultraviolet-B radiation in hairless mice. Nutr Cancer 37, 73-7.

68. Matthäus B, Özcan M. (2002) Glucosinolate composition of young shoots and flower buds of cappers (Capparis species) growing wild in Turkey. J Agric Food Chem 50, 7323-5.

69. Bonina F, Puglia C, Ventura D, Aquino R, Tortora S, Sacchi A, Saija TA, Pellegrino ML, de Caprariis P. (2002) In vitro antioxidant and in vivo photoprotective effects of a lyophilized extract of Capparis spinosa L buds. J Cosmet Sci 53, 321-35.

70. Aquino R, Morelli S, Tomaino A, Pellegrino M, Saija A, Grumetto L, Puglia C, Ventura D, Bonina F. (2002) Antioxidant and photoprotective activity of a crude extract of Culcitium reflexum H.B.K leaves and their major flavonoids. J Ethnopharmacol 79, 183-91.

71. Saliou C, Rimbach G, Moini H, McLaughlin L, Hosseini S, Lee J, Watson RR, Packer L. (2001) Solar ultraviolet-induced erythema in human skin and nuclear factor-kappa-B-dependent gene expression in keratinocytes are modulated by French maritime pine bark extract. Free Radic Biol Med 30, 154-60.

72. Rohdewald P. (2002) A review of the French maritime pine bark extract (Pycnogenol $\AA$ ), a herbal medication with a diverse clinical pharmacology. Int J Clin Pharmacol Ther 40, 158-68.

73. Blazso G, Gabor M, Rohdewald P. (1997) Antiinflammatory activities of procyanidin-containing extracts from Pinus pinaster Ait. after oral and cutaneous application. Pharmazie 52, 380-2.

74. Hibatallah J, Cauduner C, Poelman MC. (1999) In vivo and in vitro assessment of the free radical scavenger activity of Ginkgo flavone glycosides at high concentration. Pharm Pharmacol 51, 1435-40.

75. Ozkur MK, Bozkurt MS, Balabanli B, Aricioglu A, Ilter N, Gürer MA, Inalöz HS. (2002) The effect og Egb 761 on lipid peroxide levels and superoxide dismutase activity in sunburn. Photodermatol Photoimunol Photomed 18, 117-120.

76. Aricioglu A, Ozkur MK, Bozkurt MS, Balabanli B, Kilinc M, Nazaroglu NK, Türközkan N. (2001) Changes in zinc levels and superoxide dismutase activities in the skin of acute, ultraviolet-Birradiated mice after treatment with Gingko biloba extract. Biol Trace Elem Res 80, 175-9.

77. Zhao J, Wang J, Chen Y, Agarwal R. (1999) Anti-tumor-promoting activity of polyphenolic fraction isolated from grape seeds in the mouse skin two-stage initiation-promotion protocol and identification of B5-3'-gallate as the most effective antioxidant constituent. Carcinogenesis 20, 1737-45.

78. Bagchi D, Ray SD, Bagchi M, Preuss HG, Stohs SJ. (2002) Mechanistic pathway of antioxidant cytoprotection by novel IH636 grape seed proanthocyanidin extract. Indian J Exp Biol 40, 717-26.

79. Mittal A, Elmets CA, Katiyar SK. (2003) Dietary feeding of proanthocyanidins from grape seeds prevents photocarcinogenesis in SKH-1 hairless mice: relationship to decreased fat and lipidperoxidation. Carcinogenesis 24, 1379-88,

80. Carin M, Aldini G, Orioli M, Facino RM. (2002) Antioxidant and photoprotective activity of a lipophilic extract containing neolignans from Krameria triandra roots. Planta Med 68, 193-7.

81. Kim YH, Yang HE, Kim JH, Heo MY, Kim HP. (2002) The extract flowers of Prunus persica, a new cosmetic ingredient protect against solar ultraviolet-induced skin damage in vivo. J Cosmet Sci 53, 27-34.

82. Kim YH, Yang HE, Park BK Heo MY, Kim HP. (2000) Protection of the flowers of Prunus persica extract from ultraviolet B-induced damage of normal human keratinocytes. Arch Pharm Res 23, 396-400.

83. Heo MY, Kim SH, Yang HE, Lee SH, Jo BK, Kim HP. (2001) Protection against ultraviolet $\mathrm{B}$ - and $\mathrm{C}$-induced DNA damage and skin carcinogenesis by the flowers of Prunus persica extract. Mutat Res 496, 47-59.

84. Hachiya A, Kobayashi A, Ohuchi A, Kitahara T, Takema Y. (2001) The inhibitory effect of an extract of Sanguisorba officinalis L. on ultraviolet B-induced pigmentation via the suppression of endothelin-converting enzyme-1 a. Biol Pharm Bull 24, 688-92.

85. Mimaki Y, Fukushima M, Yokosuka A, Sashida Y, Furuya S, Sakagami H. (2001) Triterpene glycosides from the roots of Sanguisorba officinalis. Phytochemistry 57, 773-9.

86. Tsukahara K, Moriwaki S, Fujimura T, Takema Y. (2001) Inhibitory effect of an extract of Sanguisorba officinalis L. on ultraviolet-Binduced photodamage of rat skin. Biol Pharm Bull 24, 998-1003.

87. Bonina F, Puglia C, Tomaino A, Saija A, Mulinacci N, Romani A, Vincieri FF. (2000) In vitro antioxidant and in vivo photoprotective effect of three lyophilized extracts of Sedum telephium L. leaves. J Pharm Pharmacol 52, 1279-85. 